\title{
A Study on Improvement of Fatigue Life of materials by Surface Coatings
}

\author{
Samatham Madhukar ${ }^{*}$, Birudala Raga Harshith Reddy ${ }^{\ddagger}$, Gyara Ajay Kumar ${ }^{\dagger}$, Ramawath Prashanth Naik ${ }^{\dagger}$
}

†Department of Mechanical Engineering, University College of Engineering, Osmania University, Hyderabad, India

‡Department of Mechanical Engineering, Vidya Jyothi Institute of Technology, Hyderabad, India

Received 01 Nov 2017, Accepted 31 Dec 2017, Available online 02 Jan 2018, Vol.8, No.1 (Jan/Feb 2018)

\begin{abstract}
Fatigue failure is one of the main reasons for the mechanical failure in engineering materials. To improve the fatigue strength of the material one of the most used method is surface treatment of the materials in which hardness, wear resistance and aesthetics is improved. In this paper the different methods of surface coatings, types of fractures that occur in the material during fatigue testing and effect of the fatigue life on the material is studied.
\end{abstract}

Keywords: Fatigue Life, Surface Coating, Fracture

\section{Introduction}

Metal fatigue involves the initiation and growth of cracks under the action of cyclic stresses caused by repeated application of service loads. Residual stresses remaining from fabrication also play an important role in aggravating metal fatigue. Metal fatigue takes on greater importance with increasing yield strength level because higher strength alloys seldom, if ever, offer superior fatigue crack growth resistance as compared to lower strength materials, yet are expected to sustain higher working stresses in service. The result of this fact is a tendency to over work high-strength alloys in fatigue situations, thus hastening fatigue failure. Fatigue is by far the most common causes of failure for mechanical components (about $80 \%$ of all the fractures of metals ), and it is the most feared one, since it "occurs suddenly without any noticeable plastic deformation, i.e. without warning". Fatigue starts when a load is high enough to cause plastic deformation on a component, even when it happens only at a small volume of the material, i.e. localized plastic deformation could occur at the highest stress location. When such load is repeated cyclically, the damage accumulates and eventually a crack is formed. If the cyclic load continues, the length of the crack increases until the stress on the component is high enough to cause its sudden fracture.

The phenomenon of fatigue is generally divided into three steps: (1) crack initiation, (2) crack

*Corresponding author Samatham Madhukar (ORCID ID: 00000002-0636-568X), Gyara Ajay Kumar and Ramawath Prashanth Naik are PG Scholars; Birudala Raga Harshith Reddy is a UG Scholar

DOI: https://doi.org/10.14741/ijcet.v8i01.10878 growth/propagation and (3) final fracture. The first two steps of the process are not easy to characterize and a great amount of work on research has been performed to try to understand the mechanisms involved on each one of them; it is even hard to identify a sharp limit to divide when the crack initiation ends and the crack propagation starts. The four main parameters can influence the fatigue strength:

- Stress difference, or as most often called stress range,

- Structural detail geometry,

- Material characteristics,

- Environment

The typical fatigue behavior of most metals at dry conditions shows a stress level low enough at which the metal will no longer fail under fatigue, and it is said that the material shows infinite life. For instance, in Figure 4 a runout (no failure) is observed for each of the curves at certain stress level; taking the unnotched curve as example, the runout is present at $345 \mathrm{MPa}$. This maximum stress that the material can endure without failure is called fatigue (endurance) limit. Below this stress level there is a $50 \%$ probability that no failure will occur on a material at the same conditions. Most nonferrous metals and ferrous metals under corrosive environments do not exhibit an endurance limit. In such cases, the S-N curve does not even out at certain stress value, but instead it continues falling at a slow rate at high number of cycles . When this happens, fatigue strength, rather than fatigue limit, is reported. Fatigue strength is defined as the stress level that a material can withstand to reach a defined number of cycles, generally enough to be 
considered as 'infinite life'. In these cases, the plot must specify the number of cycles at which the fatigue strength is reported. A typical endurance limit behavior is shown in Figure 5 for AISI 1045 steel; in the same plot, the constant drop in stress to reach longer life can be seen for aluminum 2024-T6.

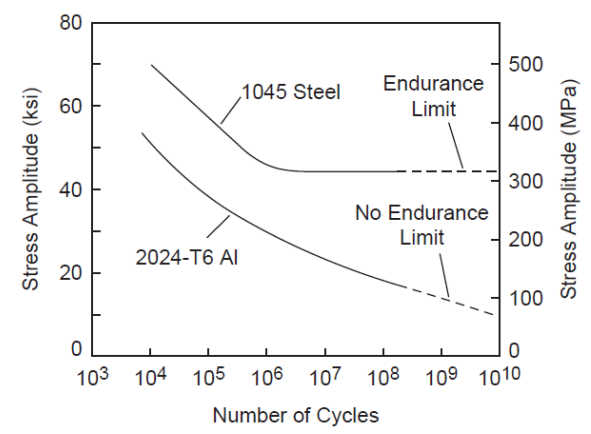

Figure 1 Comparison of steel and aluminum fatigue behavior

One of the methods to improve the fatigue life of the materials is surface treatments, sometimes referred to as post-processing. They play a very important role in the appearance, function and life of the product. Broadly, these are processes that affect either a thin layer on the surface of the part itself, or add a thin layer on top of the surface of the part. There are different coating and surface treatments processes, with different applications, uses, etc. The important uses include:

- Improving the hardness

- Improving the wear resistance

- Controlling friction, Reduction of adhesion, improving the lubrication, etc.

- Improving corrosion resistance

- Improving aesthetics

This Paper reviews the different types of surface coating methods and their effect on the fatigue life of the materials.

\section{Literature review}

M. A. Rahmat et.al ( M. A. Rahmat, et.al , 2016 ) studied the performance of hard PVD coatings on the fatigue life of notched specimens of AISI P20 tool steel and number of surface property measurements were also carried out to affirm the coating's superior surface properties and made the conclusions that Multilayer TiAlN/CrN coatings exhibited higher hardness, elastic modulus, as well as micro strain and smaller grain size compared with those of monolayer TiAlN coatings .

D. Arola et.al (D. Arola , et.al , 2006 ) conducted an experimental investigation on the effects of AWJ peening on the residual stress, surface roughness and fatigue strength of selected orthopedic metals and concluded that AWJ peening resulted in an increase in the fatigue strength of AISI 304 and Ti6Al4V. The fatigue strength also increased the most with conditions that maximized the compressive residual stress despite the large increase in surface roughness.

Weimin Zhao et.al studied the Effects of Thermally Sprayed Aluminum Coating on the Corrosion Fatigue Behavior of X80 Steel in 3.5 wt.\% $\mathrm{NaCl}$ and concluded that it could significantly improve the corrosion fatigue life of steel substrates, and this influence would be enhanced by decreasing applied stress. However, the crack growth rate of aluminum coated X80 steel was slightly higher than that of bare X80 steel.

Ali S.Yasir et.al, ( Ali S.Yasir, et.al , 2014 ) studied fatigue life of steel bars by using Nano-coating technology and concluded that fatigue test shows the positive effect of Nano-coating layers of zinc oxide ( $\mathrm{ZnO})$ on the fatigue life of rotating steel bars. The improvement in fatigue life of rotating steel bar may be reached to about 4-times as nano-coat will reduce the ability of initiation and growing of micro cracks on the steel bar surface that may causes the fatigue failure during rotating under bending load of (150N).

Xi-Shu Wang et.al (Xi-Shu Wang et.al, 2014) studied the effects of different oxide coatings on the fatigue performance of 2024-T4 aluminum and concluded that it is possible to enhance the fatigue performance of 2024-T4 aluminum alloy by using the surface treatment of the PEO coating with the impregnation of epoxy resin.

R. Ebara et.al ( R. Ebara, et.al , 2012 ) studied the Improvement of corrosion fatigue strength of materials by various surface treatments and concluded that the effective coating to improve corrosion fatigue strength should be of very low porosity and firmly adhesive to the base metal and suggested that more microscopic studies are needed to develop a corrosion resistant coating in surely improving long-term corrosion fatigue strength of materials.

\section{Surface Coatings}

\subsection{Mechanical hardening of the surface}

These methods apply mechanical impulses (e.g. light hammering) on the surface of a metallic part. This hammering action causes tiny amount of plastic flow on the surface, resulting in the work-hardening of the surface layer due to the introduction of compressive residual stresses. Examples of these processes include Shot peening (uses tiny balls of metal or ceramic), Water-jet peening (uses a jet of water at high pressures, e.g. $400 \mathrm{MPa}$ ), or Laser peening (surface is hit by tiny impulses from a laser) - an expensive process used to improve fatigue strength of jet fan blades and turbine impellers. Another method is explosive hardening, where a layer of explosive coated on the surface is blasted - the resulting impact results in tremendous increase in the surface hardness. This method is used to harden the surface of train rails (Sumith Kumar, et.al, 2017) 


\subsection{Case hardening}

This is a very common process that is used to harden the outer surface of parts such as gear teeth, cams, shafts, bearings, fasteners, pins, tools, molds, dies etc. In most of these types of components, the use involves dynamic forces, occasional impacts, and constant friction. Therefore the surface needs to be hard to prevent wear, but the bulk of the part should be tough (not brittle); this is achieved best by case hardening.( Lonyuk B , et.al , 2001 ) There are several types of case hardening: in most cases, the chemical structure of the metal is changed by diffusing atoms of an alternate element which results in alterations to the microstructure on the crystals on the surface. Most of these processes are used to case harden steel and other iron alloys, including low carbon steels, alloy steels, tool steels etc (Yerokhin A.L , et.al, 2005)

\begin{tabular}{|c|c|c|}
\hline Process & Procedure & Applications \\
\hline Carburizing & $\begin{array}{l}\text { Low-carbon steel part in } \\
\text { oven at } 870-950^{\circ} \mathrm{C} \text { with } \\
\text { excess } \mathrm{CO}_{2}\end{array}$ & $\begin{array}{c}\text { Gears, camshafts, } \\
\text { bearings }\end{array}$ \\
\hline $\begin{array}{c}\text { Carbo } \\
\text { Nitriding }\end{array}$ & $\begin{array}{c}\text { Low-carbon steel part in } \\
\text { oven at } 800-900^{\circ} \mathrm{C} \text { with } \\
\text { excess } \mathrm{CO}_{2} \text { and } \mathrm{NH}_{3}\end{array}$ & Nuts, bolts, gears \\
\hline Cyaniding & $\begin{array}{c}\text { Low-carbon steel } \\
\text { parting bath of cyanide } \\
\text { salts with } 30 \% \mathrm{NaCl}\end{array}$ & $\begin{array}{l}\text { nuts, bolts, gears, } \\
\text { screws }\end{array}$ \\
\hline Nitriding & $\begin{array}{c}\text { Low-carbon steel part in } \\
\text { oven at } 500-600^{\circ} \mathrm{C} \text { with } \\
\text { excess } \mathrm{NH}_{3}\end{array}$ & tools, gears, shafts \\
\hline Bronzing & $\begin{array}{l}\text { Part heated in oven with } \\
\text { Boron containing gas }\end{array}$ & Tool and die steels \\
\hline
\end{tabular}

\subsection{Thermal spraying}

Metal is melted in a specially designed spray gun (using oxy-fuel, plasma, or other means to heat the sprayed metal till it melts). High pressure gas then sprays the liquid metal, depositing a layer on top the part similar to a painting process (J. Jagadesh Kumar, et.al , 2017)

\subsection{Vapor deposition}

In these processes, the layer of deposited material is very thin - only a few microns. In the vacuum evaporation process, the metal to be deposited is heated in an enclosed oven at high temperature and very low pressure; some of the metal vapor deposits as a thin layer on the part. The surface can be coated not only with metal, but also with some carbides, nitrides, or ceramics. Typical applications include surface coating of cutting tools, e.g. drills, reamers, punches, dies etc.

\subsection{Electroplating}

This is a process by which a thin layer of metal is deposited on the surface of an electrically conducting part. The part is used as a cathode, and the depositing material forms the anode. The electrodes are dipped in a solution of the appropriate salt, such that on application of voltage, the metal from the anode is dissolved into the solution, and deposited on the cathode. A simple example of this process is copper plating using $\mathrm{CuSO}_{4}$ solution, using Copper anodes.

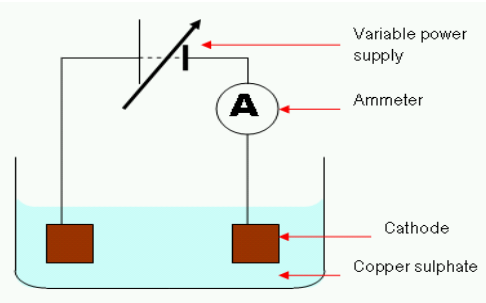

Figure 2 Copper plating

\subsection{Electroless plating}

In this case, the plating is achieved by a purely chemical reaction in the solution that causes the metal to be deposited. This process can be used to plate nonconducting parts with a layer of metal. The most common use of this process is deposition of Nickel -the reduction of Nickel chloride in solution by Sodium hypophosphite, which causes $\mathrm{Ni}$ metal to be deposited on the part. The deposited metal is not in crystalline form, so this process is followed by heat-treatment and quenching. Ni-coating using this method is used for making tool coatings that are quite hard (up to 1000 HV).

\subsection{Anodizing}

This is a very common process - many common Aluminum parts are surface treated by anodizing to give them a different color (usually black, red, blue, etc). The process uses the metal part as an anode; using electrolytic process, a layer of hard metal oxide is formed at the anode (i.e. on the surface of the part). Common examples include aluminum parts, such as picture frames, car-body parts, door-knobs and other building fixtures, bathroom fixtures and racks, sporting goods, e.g. baseball bats, and so on (Jason J Spice, et.al, 2002)

\section{Fractures Occurred In Fatigue Testing}

The different types of fractures that occur in the fatigue testing are:

a) Brittle fracture

b) Ductile fracture

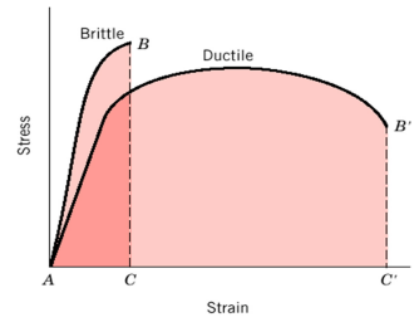

Figure 3 Comparison of Ductile and Brittle fracture 


\subsection{Ductile Fracture}

Ductile fracture involves a large amount of plastic deformation and can be detected beforehand. The different types of ductile fractures are shown in the Figure 4. (Rishi Kumar Srivastava , et.al , 2017)
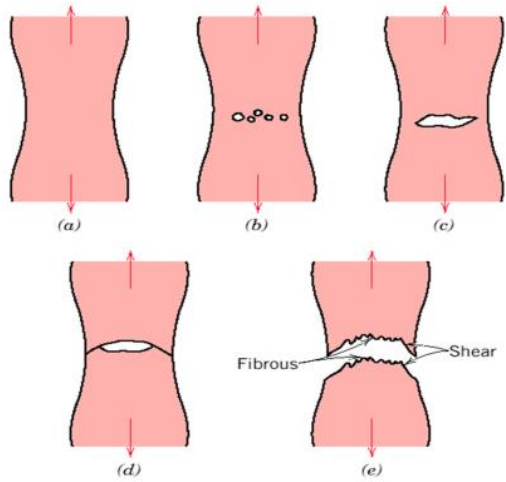

Figure 4 (a) Necking, (b) Cavity Formation, (c) Cavities coalesce _form crack, (d) Crack propagation, (e) Fracture

\subsection{Brittle Fracture}

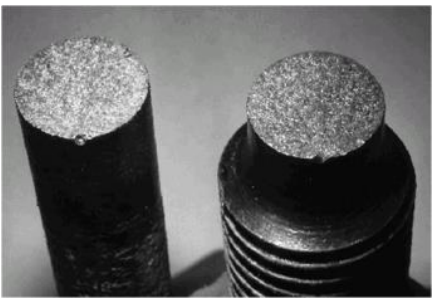

Figure 5 Brittle Fracture

The important characteristics of brittle fracture are

- Crack propagation is fast

- Propagates nearly perpendicular to direction of applied stress

- Often propagates by cleavage - breaking of atomic

- Bonds along specific crystallographic planes

- No appreciable plastic deformation

The two main different types of brittle fractures are

A. Transgranular fracture: Cracks pass through grains. Fracture surface: faceted texture because of different orientation of cleavage planes in grains.

B. Intergranular fracture: Crack propagation is along grain boundaries (grain boundaries are weakened/ embrittled by impurity segregation etc.)

\section{Conclusions}

The following conclusions can be made after reviewing the different works
- $\quad$ The improvement in the fatigue life of the material is seen when it coated.

- Improvement in the wear resistance and surface hardness of the material which is coated is seen.

- It is seen that in the case of the specimens tested at LCF, the brittle surface of the coated Specimens caused very little or no yielding at the notch tip surface, thus easily initiating.

\section{Acknowledgements}

The authors express their thanks to U.Ashok Kumar, Assistant Professor , University college of Engineering , Osmania University, Dr.V.V.Satyanarayana ,Professor and J. Jagadesh, Associate Professor, Vidya Jyothi Institute of Technology, Aziz Nagar, Hyderabad for guidance and providing us the valuable suggestions

\section{References}

M. A. Rahmat, R. N. Ibrahim, R. H. Oskouei and A. R. Bushroa (2015) Fatigue life behaviour of TiAlN and TiAlN/CrN coated notched P20 steel Specimens Wiley Publishing Ltd. Fatigue Fract Engng Mater Struct, 2016, 39, 57-67

Sumith Kumar, Pusuluri Sriharsha, Samatham Madhukar and Birudala Raga Harshith Reddy (June 2017) “Experimental Investigation on Ceramic Surface Coatings on Aluminum using Detonation Gun" ijcet, Vol.7, No.3

D. Arola, A. E. Alade, and W. Weber (2006) Improving Fatigue Strength of Metals using Abrasive water jet peening, Machining Science and Technology, 10:197-218Copyright, Taylor \& Francis Group, LLC

Weimin Zhao, Timing Zhang, Ruofei Xin, Manman Wang, Hua Ai, Jianbo Sun, and Yong Wang (2015) Effects of Thermally Sprayed Aluminum Coating on the Corrosion Fatigue Behavior of X80 Steel in 3.5 wt.\% NaCl, Journal of Thermal Spray Technology ,974-Volume 24(6) August

Ali S.Yasir (2014) Improving the fatigue life of steel bars by using Nano-coating technology International Journal of Engineering \& Technology, 3 (4) 523-528

Xi-Shu Wang , Xing-Wu Guo, Xu-Dong Li and Dong-Yun Ge Improvement on the Fatigue Performance of 2024-T4 Alloy by Synergistic Coating Technology, materials ISSN 1996-1944 www.mdpi.com/ journal/materials, 7, 35333546; doi:10.3390/ ma7053533

R. Ebara (2001) Improvement of corrosion fatigue strengthof materials by various surface treatments Transactions on Engineering Sciences vol 33, WIT Press, www.witpress.com, ISSN 1743-3533

Lonyuk, B.; Apachitei, I.; Duszczyk, J. (2007) The effect of oxide coatings on fatigue properties of 7475-T6 aluminium alloy. Surf. Coat. Technol, 201, 8688-8694.

Yerokhin, A.L.; Shatrov, A.; Samsonv, V.; Shashkov, P.; Pikington, A.; Leyland, A.; Matthews, A. (2005), Oxide ceramic coatings on aluminium alloys produced by a pulsed bipolar plasma electrolytic oxidation process. Surf. Coat. Technol., 199, 150-157.

Sanchette, F., Ducros, C., Schmitt, T., Steyer, P. and Billard, A.(2011) Nanostructured hard coatings deposited by cathodic arc deposition: from concepts to applications. Surf. Coat. Technol.,205, 5444-5453.

Oskouei, R. H. and Ibrahim, R. N. (2011) Restoring the tensile properties of PVD-TiN coated Al 7075-T6 using a post heat treatment. Surface \& Coatings Technology 
Rishi Kumar Srivastava, Syed Nizamulla, J. Jagadesh Kumar, G. Ravi Teja (November -2017) , Fatigue life prediction of tibia and fibula bones using finite element method, International Journal of Advance Engineering and Research Development Volume 4, Issue 11.

J. Jagadesh Kumar, G Diwakar \& V. V. Satyanarayana (Dec 2017), Corrosion fatigue of welded joints in marine and naval structures: A review, International Journal of Mechanical and Production Engineering Research and Development (IJMPERD) ISSN (P): 2249-6890; ISSN (E): 2249-8001 Vol. 7, Issue 6, , 155-162
Rahmat, M. A., Oskouei, R. H., Ibrahim, R. N. and SinghRaman, R. K. (2013) The effect of electroless Ni-P coatings on the fatigue life of Al 7075-T6 fastener holes with symmetrical slits. Int. J. Fatigue, 52, 30-38.

Shine U. et al (2008), Fatigue Failure of Structural Steel Analysis Using Fracture Mechanics, World Academy of Science, Engineering and Technology Vol.46..

Jason J Spice. et al. (2002) Optimized Carburized Steel Fatigue Performance as Assessed with Gear and Modified Brugger Fatigue Tests, Society of Automotive Engineers Inc,. 